\title{
Early impact on sleep and mental health during the mandatory social isolation of COVID-19 outbreak: an observational cross- sectional study carried out in Argentina
}

Stella Maris Valiensi ${ }^{1}$ Agustín L. Folgueira ${ }^{1}$

Arturo Garay ${ }^{2 *}$

${ }^{1}$ Hospital Italiano, Buenos Aires, Argentina, Neurology-Sleep Medicine Ciudad de Buenos Aires - Please select an option below - Argentina.

${ }^{2}$ Centro de Educación Médica e Investigaciones Clínicas "Norberto Quirno” (CEMIC), Neurology- Sleep Medicine - Ciudad de Buenos Aires

- Please select an option below Argentina.

\footnotetext{
*Corresponding author:

Arturo Garay

E-mail: adcgaray@gmail.com
}

Received: November 17, 2020;

Accepted: March 8, 2021.

DOI: $10.5935 / 1984-0063.20200121$

\begin{abstract}
Introduction: The mandatory social isolation (MSI) due to the pandemic caused by COVID-19 in the world produced many changes in sleep and different areas of mental health. Objectives: To evaluate the early effects of MSI on sleep, anxiety, and depression in Argentina. Material and Methods: An anonymous observational cross-sectional web-based study was distributed throughout the country and was completed by 2,594 respondents to analyze demographic information, quality of sleep, REM sleep-related events, depressive, and anxiety symptoms. Results: The study revealed that $53,21,22,23$, and $16 \%$ of people surveyed were poor sleepers, had dream-related behaviors, nightmares, depression, and anxiety symptoms, respectively. Multivariate logistic regression showed a positive correlation between anxiety, being a poor sleeper, and having nightmares. Conclusion: We identified the early effects of MSI on sleep quality, dreaming activity, anxiety, and depression in Argentina during the COVID-19 outbreak. Our findings can be used to formulate sleep and psychological interventions to improve mental health during the pandemic and post-pandemic times.
\end{abstract} Keywords: REM Sleep Parasomnias; Coronavirus Infections; Anxiety Disorders; Depression; Sleep; Social Isolation. 


\section{INTRODUCTION}

By the end 2019, a new coronavirus disease (COVID-19) appeared in Wuhan, China, and rapidly spread throughout the entire globe ${ }^{1}$. As a countermeasure to the COVID-19 outbreak, quarantine was imposed in several countries. Even though quarantine is a unique and exceptional measure used to control in this case, the spread of the COVID-19 pandemic, its implementation was associated with deleterious effects on public health, mental health, and economy ${ }^{2}$. In Argentina, the presentation of the first cases was observed in the first days of March. By March 20, with the increase of COVID-19 detected cases, the national government decided to install a rather strict quarantine including mandatory social isolation (MSI), closure of borders, cessation of activities except for those activities considered essentials. This period included the time of maximum restriction of the MSI (phase I) in our country from March $20^{\text {th }}$ to April $26^{\text {th }}$.

It is very well-known that social relationships are central to human well-being and are critically involved in the maintenance of health, sleep, and mental health. Interestingly, some reports of people surveyed during the COVID-19 outbreak indicates an increase of dreaming mentation and disturbed dreaming. Indeed, experiences that essentially put "the life on hold", as the COVID-19 outbreak, meaning this, separation from loved ones, lack of social interaction, confinement, loss of routine, uncertainty, and fear about the situation, economic injury, are directly related to the appearance of symptoms of insomnia, fatigue, excessive anxiety disorders, and irritability ${ }^{4-17}$.

In this observational/cross-sectional study, our purpose was to evaluate the early effects of MSI on sleep, anxiety, and depression symptoms in Argentina during the COVID-19 outbreak.

\section{MATERIAL AND METHODS}

\section{Study design and participants}

An anonymous, voluntary web-based observational cross-sectional survey was distributed through social media and email. The survey was enabled from April 13 to April 30. All subjects reported demographic and social data, COVID-19 related information, they completed questionnaires to evaluate the sleep and the presence of anxiety and depressive symptoms.

\section{Ethical statement}

This study was conducted in accordance with the declaration of Helsinki. Before starting the questionnaire, the objectives of the study were explained. Participants could withdraw from the survey at any moment without providing any justification.

\section{Measurement tools}

Sleep quality: The Spanish version of the PSQI (Pittsburgh sleep quality index) was used ${ }^{18,19}$. This is a 24 items scale that is divided into seven subcomponents (subjective sleep quality, sleep latency, sleep duration, habitual sleep efficiency, sleep disturbance, use of sleep medications, and daytime dysfunction). The score for each subcomponent ranges from 0 to 3 points. The global PSQI score ranges from 0 to 21, with higher scores indicating more severe sleep disorders. Scores of 5 or less were considered good sleepers while a score greater than 5 categorizes participants as bad sleepers ${ }^{20}$. A score of 5 to 7 was considered mild insomnia or mild sleep problem and requires the indication of medical treatment; a score of 8 to 14 implies moderate insomnia or moderate sleep problem that requires medical attention and treatment, and a score of 14 to 21 suggests a serious sleep problem ${ }^{18-21}$.

Additionally, we also asked about the nap habits during MSI: changes in frequency and/or duration of naps when compared with the period pre-COVID-19 outbreak.

To assess the dream-related behaviors ${ }^{16}$, we used a single question for REM sleep behavior Disorder (RBD1Q). Although there is some evidence showing poor performance of this tool for RBD evaluation ${ }^{22,23}$, it is validated in different languages for detecting REM sleep behavior disorders defined by a positive response and we considered is very appropriate to detect the presence of motor activity related to dreams due to its simplicity. The presence of nightmares or bad dreams was assessed by the PSQI question \#H5 and was considered positive when these events occurred one or more times a week.

To assess depression symptoms, we used the patient health questionnaire - 9 (PHQ-9) $)^{24-26}$. The PHQ is a selfadministered version of the PRIME-MD diagnostic instrument for common mental disorders. The PHQ-9 is the depression module, which scores each of the 9 DSM-IV criteria as " 0 " (not at all) to " 3 " (nearly every day). Scores range from 0 to 27 points. A PHQ- 9 score $\geq$ of 10 has a sensitivity of $88 \%$ and a specificity of $88 \%$ for "major depression". PHQ-9 scores of 5 , 10,15 , and 20 represent mild, moderate, moderately severe, and severe depression, respectively.

To detect anxiety symptoms, we used the generalized anxiety detection questionnaire (GAD-7) ${ }^{27}$. The GAD includes 7 items on a 4-point Likert scale ranging from 0 (never) to 3 (nearly every day). The total score ranges from 0 to 21 , with higher scores indicating more severe functional impairments as a result of anxiety. Scores of 5, 10, and 15 are taken as the cutoff points for mild, moderate, and severe anxiety, respectively ${ }^{27-28}$.

\section{Statistical analysis}

The results of qualitative variables were expressed as frequencies and percentages. Quantitative variables, by means and standard deviation of the mean. Trend and distribution measurements were used to describe the groups. The t-test was used to analyze the continuous variables. Analysis of variance (ANOVA) was done using the $\mathrm{R}$ language. Chi-square tests were used to compare the qualitative variables. Binary logistic regression for multivariate analysis, between sex, age, bedtime, time to get up, sleep onset latency, hours of night sleep $<6$ hours and $>10$ hours, naps, nightmares, diagnosis of depression, anxiety, and poor sleepers. All data were analyzed 
for Statistical Package with Social Science (SPSS) version 18 (SPSS 18 Chicago, IL, U.S.A, SPSS Inc.). The $p$-values of less than 0.05 were considered statistically significant.

\section{RESULTS}

We selected 2,594 participants from a total of 2,798 participants, which is $92.7 \%$ of the participants who answered the survey. Criteria for exclusion were: consecutively surveys that have equal entries were assumed to be duplicate responses and were therefore eliminated. Also, participants under 18 years of age, people who were living abroad at the time of the survey, erroneous or inconsistent data, sleep duration of fewer than 4 hours, and more than 12 hours, and naps duration greater than 3 hours were excluded.

\section{Demographic characteristics}

The demographic characteristics of participants are shown in Table 1. There were 2,594 participants in our study, 803 participants being males (31\%), 1,790 females (69\%) and $1(0.04 \%)$ non-binary.

Table 1. Demographic characteristics of the sample. Scores outcomes over a total of $\mathrm{N}=2,594$ subjects.

\begin{tabular}{l|c|c}
\hline & Mean & SD \\
\hline Age (18-85 years old) & 42 & 13 \\
COVID-19 Time exposition on healthcare & 7 & 12.4 \\
workers (hours) & n & \% \\
\hline $\begin{array}{l}\text { AMBA (Buenos Aires city and surrounding } \\
\text { Municipalities) }\end{array}$ & 745 & 28.7 \\
Buenos Aires province (outside AMBA) & 984 & 37.9 \\
Provinces (outside Buenos Aires province) & 865 & 33.3 \\
Gender & & \\
Male & 803 & 31 \\
Female & 1,790 & 69 \\
Non binary & 1 & 0.04 \\
Age & & \\
18 to 40 years old & 1,243 & 47.9 \\
40 to 55 years old & 884 & 34.1 \\
55 to 65 years old & 326 & 12.6 \\
65 to 85 years old & 141 & 5.4 \\
Employed & & \\
Healthcare workers & 710 & 27.4 \\
Employed & 1,040 & 40.1 \\
Unemployed & 844 & 32.5 \\
\hline
\end{tabular}

The mean age of the participants was 42.0 (SD: \pm 13 ) years. The most represented age range was $40-55$ years $(52.1 \%)$. Regarding their employment situation, 1,750 participants had stable jobs (27.4\% were health workers) and 844 participants $(32.5 \%)$ were unemployed.

In our study, most of the people live in AMBA (Buenos Aires city and surrounding municipalities): 745 (28.7\%) and Buenos Aires province (outside AMBA) 984 (37.9\%), while the rest, $865(33.3 \%)$ were distributed across 14 provinces (we did not receive data from one of them, Jujuy province).

\section{Survey general description}

Table 2 shows the characteristics of the overall sample related to sleep, naps, nightmares, dream-enacted behaviors by PSQI, RBDQ1 questions. The mean bedtime was 00:02 hours, the mean of sleep onset latency was prolonged (37.8min), and wake up time was at 8:29 a.m. The mean nap duration was $68 \mathrm{~min}$. (range: $5-180 \mathrm{~min}$.). Naps were reported to be more frequent in 516 surveys $(20 \%)$ and of longer duration in 756 surveys $(29 \%)$. The subjective sleep efficiency was $83.5 \%$ (range: $40-100$ ).

Table 3 shows the score outcomes for PSQI. The results shows that $47 \%$ of answers reported an increase of sleep onset latency ( $>30 \mathrm{~min} \geq 1$ night in the week). Altered sleep continuity was observed by the following: getting up at night to go to the bathroom: 1,336 answers (51.5\%); having pain: 695 answers (27\%); feeling too hot: 665 answers $(26 \%)$, feeling too cold: 630 answers $(24 \%)$. The global PSQI score of 5 or less, that were considered good sleepers corresponded to 1,219 answers (47\%).

The question about nightmares or bad dreams (PSQI\#5h), was answered positively by $22.9 \%$ of the people surveyed. For the evaluation of the presence of dream-related behaviors, we used the RBDQ1. We found that 549 (21.2\%) of the people surveyed responded positively to this question.

Table 4 shows the analysis of scores of PSQI (sleep quality), PHQ-9 (depression), and GAD-7 (anxiety). The results revealed that 1,375 surveys (53\%) were poor sleepers and $31.1 \%$ had mild insomnia, 32,4\% had moderate insomnia, and 2.1\% had a serious sleep problem. $21.1 \%$ of the people showed elevated values of depression symptoms by PHQ-9 (PHQ$9 \geq 10)$ and $16 \%$ showed elevated levels of anxiety by GAD-7 (GAD-7 score $\geq 10$ ).

Table 5 shows the relationship between the depression (PHQ-9), anxiety (GAD-7), and sleep quality (PSQI) questionnaires using univariate ANOVA (analysis post hoc Turkey test). The results indicate that there is a statistically significant positive correlation between the increase of the scores for depression and anxiety and the PSQI. The difference was significant among all PHQ-9 scores and the difference was significant between all GAD-7 severity grades (except between moderate and severe).

Table 6 shows multivariate analysis of binary logistic regression of different questionnaires over a total of $n=2,594$ subjects. Taking into account the effect of sex, age, bedtime greater than 00:00 hour, time to get up greater than 08:00 hour, sleep onset latency greater than 30 minutes, sleep duration less than 6 hours, sleep duration greater than 10 hours, take naps, the presence of nightmares, diagnosis of depression, anxiety and poor sleepers, we found as an important correlation that the latency to sleep greater than 30 minutes, the risk of being a poor sleeper was 3.51 and 3.69 the risk, for sleeping less than 6 hours. Having depression (PHQ-9 $\geq 10$ ) the risk was 2.99 , and having anxiety $(\mathrm{GAD} \geq 10)$ the risk of being a bad sleeper was 1.78 . When analyzing nightmares, the risk 
Table 2. Full sample of sleep and naps questions. Scores outcomes over a total of $N=2,594$ subjects.

\begin{tabular}{|c|c|c|c|c|c|c|c|c|}
\hline & & & & & Min & Max & Mean & SD \\
\hline \multicolumn{5}{|l|}{ Bedtime (hh:min) } & 20:00 & 04:00 & 00:02 & $1: 22$ \\
\hline \multicolumn{5}{|l|}{ Get up (hh:min) } & 04:00 & $14: 00$ & 08:29 & $1: 38$ \\
\hline \multicolumn{5}{|c|}{ Sleep duration (hh:min) } & 04:00 & $12: 00$ & 07:00 & $1: 18$ \\
\hline \multicolumn{5}{|c|}{ Time in bed (Time Down - Time Up) (hh:min) } & 04:00 & $14: 00$ & $08: 26$ & $1: 25$ \\
\hline \multicolumn{5}{|c|}{ Sleep onset latency $(\mathrm{min})$} & 0 & 240 & 37.82 & 40.35 \\
\hline \multicolumn{5}{|c|}{ Latency time to get up (min) } & 0 & 240 & 23.06 & 24.01 \\
\hline \multicolumn{5}{|c|}{ Sleep efficiency $(\%)$} & 40 & 100 & 83.5 & 13.18 \\
\hline \multicolumn{5}{|c|}{ Nap duration time (min) } & 5 & 180 & 67.99 & 36.3 \\
\hline \multirow[b]{3}{*}{ Bedtime: no changes } & \multicolumn{8}{|c|}{ In relation before MSI } \\
\hline & $\mathbf{n}$ & \multicolumn{2}{|l|}{$\%$} & $\mathbf{n}$ & \multicolumn{2}{|c|}{$\%$} & $\mathbf{n}$ & $\%$ \\
\hline & 1083 & 41.8 & Naps Frequency: not nap & 1114 & \multicolumn{2}{|c|}{ 42.9 Naps Duration: not nap } & 1114 & 42.9 \\
\hline \multirow{3}{*}{$\begin{array}{l}\text { Bedtime: earlier } \\
\text { Bedtime: later }\end{array}$} & 826 & 31.8 & Naps Frequency: no changes & 753 & \multicolumn{2}{|c|}{29 Naps Duration: no changes } & 516 & 19.9 \\
\hline & & & Naps Frequency: decreased & 360 & \multirow{2}{*}{\multicolumn{2}{|c|}{$\begin{array}{l}\text { 13.9 Naps Duration: shorter } \\
\text { 14.1 Naps Duration: longer }\end{array}$}} & 630 & 24.3 \\
\hline & 685 & 26.4 & Naps Frequency: increased & 367 & & & 334 & 12.9 \\
\hline
\end{tabular}

Table 3. Full sample of PSQI. Scores outcomes over a total of $\mathrm{N}=2,594$ subjects.

\begin{tabular}{|c|c|c|}
\hline & Mean & SD \\
\hline PSQI\#1 Bed Time (hh:mm) & 00:02 & $1: 22$ \\
\hline PSQI\#2 Sleep Onset Latency (minutes) & 37.82 & 40.4 \\
\hline PSQI\#3 Wake Up Time (hh:mm) & $08: 29$ & $1: 38$ \\
\hline \multirow[t]{2}{*}{ PSQI\#4 Sleep duration time (hh:mm) } & 07:00 & $1: 18$ \\
\hline & $\mathbf{n}$ & $\%$ \\
\hline PSQI\#5a Sleep latency $>30 \mathrm{~min} \geq 1 / 7$ days & 1,220 & 47 \\
\hline PSQI \#5b Wake up in the night $\geq 1 / 7$ days & 1,514 & 58.4 \\
\hline PSQI \#5c Getting up at night to go to the bathroom $\geq 1 / 7$ days & 1,336 & 51.5 \\
\hline PSQI\#5d Not being able to breathe well $\geq 1 / 7$ days & 219 & 8.4 \\
\hline PSQI \#5e To cough or to snore loudly $\geq 1 / 7$ days & 400 & 15.4 \\
\hline PSQI \#5f To feel too cold $\geq 1 / 7$ days & 630 & 24.3 \\
\hline PSQI \#5g To feel too hot $\geq 1 / 7$ days & 665 & 25.6 \\
\hline PSQI \#5h To have nightmares or bad dreams $\geq 1 / 7$ days & 593 & 22.9 \\
\hline PSQI \#5i To have pain $\geq 1 / 7$ days & 695 & 26.8 \\
\hline PSQI \#5j Other reason(s) $\geq 1 / 7$ days & 466 & 18 \\
\hline PSQI \# 6 Sleep quality overall fairly or very bad & 891 & 34.3 \\
\hline PSQI \#7 Take medicine to sleep $\geq 1 / 7$ days & 357 & 13.8 \\
\hline $\begin{array}{l}\text { PSQI \#8 Drowsiness while driving, eating, or doing other } \\
\text { activities } \geq 1 / 7 \text { days }\end{array}$ & 222 & 8.6 \\
\hline $\begin{array}{l}\text { PSQI \#9 Encouragement to carry out activities of daily } \\
\text { living } \geq 1 / 7 \text { days }\end{array}$ & 511 & 19.7 \\
\hline PSQI score $\leq 5:$ Good sleepers & 1,219 & 47 \\
\hline PSQI score > 5: Poor sleepers & 1,375 & 53 \\
\hline Dreams-related behaviors: RBDQ1 & 549 & 21.2 \\
\hline
\end{tabular}

of having them was 2.02 higher, in those with dream enacting behaviors by positive RBDQ1.

Taking into account the same variables analyzed, we found that being under 55 years of age the risk was 2.13 higher in those who presented depression, as well as those who slept more than 10 hours, the estimated risk was 2.47 , in those who had anxiety. The risk of having depression was 7.4 times higher, and being a poor sleeper the risk was 2.4 times higher than good sleepers.

Taking into account the same variables, we found that having depression, the risk was 7.51 times higher in those who presented anxiety and being a bad sleeper the risk was 2.99 in those who were anxious.

\section{DISCUSSION}

Our study attempts to give a first look at early manifestations of sleep alterations from a multidimensional perspective about symptoms of insomnia, nightmares, dreamrelated behaviors and depression and anxiety symptoms during the first month of MSI in Argentina.

One of the first findings was that more than half of the population was poor sleepers reporting in their surveys the following: prolonged sleep onset latency, prolonged time to bedtime and late get up, an increase of the number and time duration of sleep naps and in the number of awakenings mainly produced by cough access, snore or nightmares. This population of poor sleepers was correlated with higher levels of anxiety and depression during MSI. Besides, almost half of the population reported not being able to fall asleep during the first hour, pointing out a probable phase delay. This in agreement with the well-known observation that the effect of physical distancing and the excessive use of ALAN (Artificial Avant Light) could be related to an increased risk of circadian rhythm dysregulation ${ }^{30-31}$.

In pre-COVID-19 times, we estimated that about $20 \%$ of the general population of Argentina sleep poorly, a percentage that could be increased up to $50 \%$ or more in some specific groups (drivers, adolescents, population with a low socioeconomic level) ${ }^{32}$. In the present study, we found that the total subjective sleep time was within the values considered normal for adults ${ }^{33}$ and that the disturbance of the sleep continuity was the hallmark of this issue. To compare the prevalence of sleep quality before the MSI, in the general population, we found that, to our knowledge, there were no studies in Argentina reporting this condition by PSQI. In our study, we observed a huge impact on sleep quality, i.e., we found that $64.3 \%$ of the population had insomnia symptoms ranging from mild to severe insomnia symptoms during approximately the first month of MSI. To compare the prevalence of insomnia to our knowledge, there were no studies in Argentina reporting this condition before the 
Table 4. Analysis of the scores according severity of PSQI (sleep quality), PHQ-9 (depression), and GAD-7 (anxiety). Scores outcomes over a total of N=2,594 subjects.

\begin{tabular}{|c|c|c|c|c|c|c|c|c|}
\hline PSQI score & n & $\%$ & PHQ-9 score & n & $\%$ & GAD-7 score & n & $\%$ \\
\hline $0-\leq 5:$ no problem & 892 & 34.4 & 0-4: negative & 1007 & 38.8 & 0 -4: negative & 1161 & 44.8 \\
\hline 5-7: mild insomnia & 807 & 31.1 & 5-9: mild & 1039 & 40.0 & 5-9: mild & 1114 & 42.9 \\
\hline 8-14: moderate insomnia & 842 & 32.4 & 10-14: moderate & 384 & 14.8 & 10-14: moderate & 234 & 9.0 \\
\hline \multirow[t]{3}{*}{ 14-21: severe insomnia } & 54 & 2.1 & 15-19: moderately severe & 129 & 5.0 & 15-21: severe & 85 & 3.3 \\
\hline & & & 20-27: severe & 35 & 1.3 & 10-21: anxiety & 416 & 16.0 \\
\hline & & & 10-27: depression & 548 & 21.1 & & & \\
\hline
\end{tabular}

Table 5. Relationship between the depression (PHQ-9), anxiety (GAD-7) and sleep quality (PSQI) questionnaires using ANOVA univariate. Analysis post hoc Tukey Test. Scores outcomes over a total of $\mathrm{N}=2,594$ subjects.

\begin{tabular}{l|c|c|c|c}
\hline & $\mathbf{n}$ & Mean PSQI & SD & p \\
\hline Score PHQ-9 & 1007 & 4.47 & 2.61 & \\
0-4 negative & 1039 & 6.80 & 3.04 & \\
5-9 mild & 384 & 8.41 & 3.39 & 0.00 * $^{*}$ \\
10-14 moderate & 129 & 9.79 & 3.70 & \\
15-19 moderately serious & 35 & 11.83 & 3.17 & \\
20-27 severe & & & & \\
Score GAD-7 & 1161 & 4,84 & 2.81 & \\
0-4: minimal & 1114 & 7.18 & 3.33 & \\
5-10: mild & 234 & 8.79 & 3.33 & $0.00 *^{* * *}$ \\
11-15: moderate & 85 & 9.42 & 3.88 & \\
\hline 16-21: severe & & & & \\
\hline
\end{tabular}

Notes: *The difference was significant among all PHQ-9 scores; ${ }^{* *}$ The difference was significant between all GAD-7 severity grades (except between moderate and severe).

MSI. Interestingly, research carried out in the general population of Latin America, including metropolitan areas of Ciudad de México (México), Montevideo (Uruguay), Santiago de Chile (Chile), and Caracas (Venezuela), reported a prevalence of insomnia of about $34.7 \%(33.3 \% \text { to } 36 \%)^{34}$.

As for napping, $20 \%$ of people surveyed reported increasing the frequency of naps and a third sleeping more minutes than before MSI. Napping, in this study, was correlated with being bad sleepers and presenting nightmares. We did not find any previous studies that analyzed these data in Argentina.

Some informal publications and at present several scientific works reported an increase of dreaming and disturbed dreaming during the COVID-19 outbreak ${ }^{44-47}$. Our results show that more than $20 \%$ of the people surveyed responded positively about presenting dream-related behaviors by question RBDQ1. This positive answer was mostly correlated with individuals under the age of 55 years old and with those who manifested fragmenting their sleep by coughing, snoring, or nightmares. It was also positively correlated with having anxiety disorder according to GAD-7. As far we know, only a single study, performed three months after MSI, analyzed the presence of dream-enacting behaviors in health workers, with similar results ${ }^{36}$. These findings are in agreement with concepts expressed by Nielsen et al. (2019) ${ }^{16}$ in the normal population. In our sample, they could be related to the emotional impact denoted by increased anxiety and depression symptoms during
MSI stressful conditions. The necessity of characterizing the phenomenology of dream enacting behaviors had been pointed out by two recent and excellent reviews ${ }^{64.66}$.

The presence of nightmares was observed in $23 \%$ of the people surveyed. The presence of nightmares was correlated with being poorly sleeper, acting dreams by RBDQ1, having depressive symptoms, and anxiety. Nightmares are commonly defined as disturbing dreams characterized by awakening from (REM) sleep with very vivid and detailed dream recall. Dream content is typically related to threats to survival, security, or self-esteem ${ }^{36}$. For the diagnosis of nightmare disorder, dream content and the awakening must cause clinically significant distress or impairment in important areas of functioning ${ }^{37}$. At least one nightmare per week is often used as a criterion of clinical significant distress ${ }^{38}$. Anxiety or fear is often reported as the predominant emotions of nightmares; however, recent research suggests that other, less intense emotions like frustration or guilt can be involved as well ${ }^{39}$. The prevalence of frequent nightmares in the general population is about $5 \%$ in adults ${ }^{40,41}$. The theories about the origin of nightmares/bad dreams $^{42}$ are multifaceted: mechanisms for regulating emotions, mastering stress, de-somatization of affection, contextualization of the emotional, and extinction of fear memory. A failure in the mechanisms used by nightmares would predispose to their perpetuation and the possibility of developing the disease. This is very commonly observed in patients with posttraumatic stress after a few months or years after the life event and can last for several years.

In times of COVID-19 pandemic, recent publications show that the significant increase in dream recall might be explained by three factors: first, for many people, their sleep patterns have changed dramatically during the pandemic. This might be especially true among young adults, who are sleeping longer, and thus, they were able to recall more ${ }^{43}$. Second, the combination of more negatively toned dreams and more dreams relating to the pandemic should result - according to the salience hypothesis of dream recall in higher dream recall ${ }^{45}$. Lastly, one of the symptoms of insomnia is the more frequent nocturnal awakenings, which has been found to correlate with increased dream recall; thus, the increase in insomnia prevalence due to the pandemic ${ }^{7,9}$ might have also increased dream recall.

Early this year, when stay-at-home directives were put in place widely, society quite unexpectedly experienced what it was called a dream surge: a global increase in the reporting of vivid, bizarre dreams, many of which are concerned with coronavirus 
Table 6. Multivariate analysis of binary logistic regression of different questionnaires over a total of $\mathrm{N}=2,594$ subjects.

\begin{tabular}{|c|c|c|c|c|c|c|c|c|c|c|c|c|}
\hline & \multicolumn{3}{|c|}{ PSQI } & \multicolumn{3}{|c|}{ RBDQ1 } & \multicolumn{3}{|c|}{ PHQ-9 } & \multicolumn{3}{|c|}{ GAD-7 } \\
\hline & OR & IC95 & $\mathrm{p}$ & OR & IC95 & $\mathrm{p}$ & OR & IC95 & $\mathrm{p}$ & OR & IC95 & $\mathrm{p}$ \\
\hline Gender female & 1.28 & 1.1-1.6 & 0.01 & 1.50 & $1.2-1.9$ & 0.00 & 1.28 & 1.1-1.6 & 0.01 & 1.50 & $1.2-1$ & 0.00 \\
\hline Age $<55$ years old & 0.86 & $0.7-1.1$ & 0.19 & 1.76 & $1.4-2.4$ & 0.00 & 2.13 & $1.5-3$ & 0.00 & 2.47 & $1.6-3.8$ & 0.00 \\
\hline Age $\geq 65$ years old & 1.23 & $0.8-1.8$ & 0.29 & 1.74 & $1.1-2.9$ & 0.03 & 1.23 & $0.8-1.8$ & 0.29 & 1.69 & $1.1-2.6$ & 0.01 \\
\hline Bedtime $>12: 00$ p.m. & 0.79 & $0.7-0.9$ & 0.02 & 1.05 & $0.9-1.3$ & 0.65 & 1.28 & $1.0-1.6$ & 0.04 & 1.17 & $0.9-1.5$ & 0.27 \\
\hline Wake up time $>08: 00$ a.m. & 1.46 & $1.2-1.8$ & 0.00 & 1.02 & $0.8-1.3$ & 0.90 & 1.06 & $0.8-1.4$ & 0.66 & 0.74 & $0.6-1$ & 0.04 \\
\hline Sleep onset latency $>30 \mathrm{~min}$ & 3.51 & $2.9-4.2$ & 0.00 & 1.00 & $0.8-1.2$ & 0.99 & 1.19 & $0.9-1.5$ & 0.15 & 1.21 & $0.9-1.6$ & 0.15 \\
\hline Short sleeper $(<6 \mathrm{hs})$ & 3.69 & $2.7-5.1$ & 0.00 & 1.02 & $0.8-1.4$ & 0.89 & 1.54 & $1.1-2.1$ & 0.01 & 1.73 & $1.2-2.4$ & 0.00 \\
\hline Long sleeper (>10hs) & 0.70 & $0.4-1.2$ & 0.18 & 1.06 & $0.0-1.9$ & 0.83 & 2.12 & $1.2-3.8$ & 0.01 & 0.54 & $0.3-1.2$ & 0.13 \\
\hline Take naps & 1.19 & $0.9-1.4$ & 0.05 & 1.18 & $0.3-1.4$ & 0.22 & 1.26 & $1-1.6$ & 0.04 & 1.00 & $0.8-1.3$ & 1.00 \\
\hline Cough or snore $(\geq 1 / 7$ days $)$ & 1.75 & $1.4-2.3$ & 0.00 & 1.88 & $1.5-2.4$ & 0.00 & 0.97 & $0.7-1.3$ & 0.83 & 1.25 & $0.9-1.7$ & 0.18 \\
\hline Nightmares $(\geq 1 / 7$ days $)$ & 1.83 & $1.5-2.3$ & 0.00 & 2.02 & $1.6-2.5$ & 0.00 & 1.50 & $1.2-1.9$ & 0.00 & 2.12 & $1.6-2.8$ & 0.00 \\
\hline PSQI $>5$ & & & & 1.15 & $0.9-1.4$ & 0.21 & 2.97 & 2.3-3.9 & 0.00 & 1.81 & $1.4-2.4$ & 0.00 \\
\hline PHQ-9 $\geq 10$ & 2.99 & $2.3-3.9$ & 0.00 & 1.06 & $0.8-1.4$ & 0.68 & & & & 7.52 & $5.8-9.7$ & 0.00 \\
\hline$G A D \geq 10$ & 1.78 & $1.3-2.4$ & 0.00 & 1.37 & $1.0-1.8$ & 0.02 & 7.51 & $5.8-9.7$ & 0.00 & & & \\
\hline Cox y Snell coefficient & & 22.0 & & & 4.6 & & & 21.4 & & & 19.2 & \\
\hline Nagelkerke coefficient & & 29.4 & & & 7.4 & & & 33.3 & & & 32.9 & \\
\hline
\end{tabular}

and social distancing. By early April, social and mainstream media outlets had begun broadcasting the message: the world is dreaming about COVID-19. The association between nightmares and stressful situations is widely known ${ }^{45,46}$. Gupta $(2020)^{17}$ reported nightmares or disturbing dreams or nightmares in patients with posttraumatic stress disorders (PTSD), and Nielsen et al. (2020) ${ }^{47}$ reported that this increase was attributed by several authors ${ }^{48,49}$ to the economic and social consequences produced by the COVID-19 outbreak. They found that less than one-third of the population presented these REM sleeprelated events. So far, we did not find the percentage of these alterations in the world population during pandemic times in the current literature, which makes our findings interesting.

Depression is a frequent psychiatric illness characterized by depressive mood, loss of interest or pleasure, feelings of guilt, disability, sleep and appetite disturbances, lack of energy, and difficulties in concentration and there are several causes for these symptoms ${ }^{50-53}$. We noticed that it was associated with being younger than 55 years old, presenting anxiety disorders, sleeping more than 10 hours, and being bad sleepers. The anxiety is correlated with poor sleepers ${ }^{54,55}$. For this reason, we believe that reinforcing the action of external zeitgebers, such as encouraging physical activity $^{56,57}$, slowly restoring social rhythms, promoting exposure to light, maintaining regular sleeping and feeding times ${ }^{58,59}$, would help to improve mood changes. With this observation, the risk of PTSD, already identified in previous studies, emerges as an imminent problem to consider ${ }^{60,61}$. Finally, the arrival of the first cases of COVID-19 occurred months later than in China and Europe. During the first months of 2020, Argentinian people were viewers of the real consequences of the outbreak in the first world countries, hence, a state of alert and anxiety about an inevitable outcome could have been generated prematurely.

The impact observed with the scales used and its consistency with previous reports related to COVID-19/SARS/
MERS/Ebola outbreaks points to the role of the state of alert and anxiety activating the hypothalamus-pituitary-adrenal (HPA) system could promote a vicious cycle of stress and insomnia, and their consequent effects on the score of anxiety and depression ${ }^{62}$. A study conducted one week after the onset of MSI showed depressive and anxiety symptoms of $23 \%$ and $33 \%$, respectively ${ }^{63}$. The present study evidenced similar depression but less percentage in anxiety one month after the onset of MSI. Perhaps by "handling" it, through nightmares and behavioral changes of REM sleep as we have seen at approximately one month of the start of the MSI (see Table 5). Although many people tend to react resiliently to stress, others appear to display depression-related symptoms, anxiety, and sleep disorders.

The biases of this study were various, for example, it was an online self-report questionnaire which leads to a sample bias, one of this was that $69 \%$ of people surveyed were women, which should lead us to take the results of differences by gender with caution and also, we did not ask about alcohol or drugs consumption as sleep inducers, weight gain, cognitive impairment or hours to exposure to light.

Concluding, we identified for the first time, early effects of MSI on sleep quality, dream enacting behaviors, nightmares, depression, and anxiety symptoms in Argentina during the COVID-19 outbreak. Our findings can be used to formulate sleep and psychological interventions trying to improve mental health during the pandemic and post-pandemic times.

\section{CONFLICT OF INTERESTS}

The authors declare not to have any interest conflicts.

\section{REFERENCES}

1. Wang C, Horby PW, Hayden FG, Gao GF. A novel coronavirus outbreak of global health concern. Lancet. 2020 Feb;395(10223):470-3. DOI: https://doi.org/10.1016/S0140-6736(20)30185-9 
2. Brooks SK, Webster RK, Smith LE, Woodland L, Wessely S, Greenberg $\mathrm{N}$, et al. The psychological impact of quarantine and how to reduce it: rapid review of the evidence. Lancet. 2020 Mar;395(10227):912-20. DOI: https://doi.org/10.1016/S0140-6736(20)30460-8

3. Ministerio de Salud (AR). Reporte diário vespertino No. 216 Situación de COVID-19 en Argentina - 30/06/2020. Buenos Aires: Ministerio de Salud; 2020 .

4. Huang Y, Zhao N. Generalized anxiety disorder, depressive symptoms and sleep quality during COVID-19 outbreak in China: a web-based cross-sectional survey. Psychiatry Res. 2020;288:112954.

5. Casagrande M, Favieri F, Tambelli R, Forte G. The enemy who sealed the world: effects quarantine due to the COVID-19 on sleep quality, anxiety, and psychological distress in the Italian population. Sleep Med. 2020;75:12-20. DOI: https://doi.org/10.1016/j.sleep.2020.05.011

6. Voitsidis P, Gliatas I, Bairachtari V, Papadopoulou K, Papageorgiou G, Parlapani E, et al. Insomnia during the COVID-19 pandemic in a Greek population. Psychiatry Res. 2020;289:113076. DOI: https://doi. org/10.1016/j.psychres.2020.113076

7. Zhang C, Yang L, Liu S, Ma S, Wang Y, Cai Z, et al. Survey of insomnia and related social psychological factors among medical staff involved in the 2019 novel coronavirus disease outbreak. Front Psychiatry. 2020 Apr;11:306. DOI: https://doi.org/10.3389/fpsyt.2020.00306

8. Dong L, Bouey J. Public mental health crisis during COVID-19 pandemic, China. Emerg Infect Dis. 2020 Jul;26(7):1616-8. DOI: https://doi.org/10.3201/eid2607.200407

9. Pappa S, Ntella V, Giannakas T, Giannakoulis VG, Papoutsi E, Katsaounou P. Prevalence of depression, anxiety, and insomnia among healthcare workers during the COVID-19 pandemic: a systematic review and meta-analysis. Brain Behav Immun. 2020 Aug;88:901-7. DOI: https://doi.org/10.1016/j.bbi.2020.05.026

10. Ho CS, Chee CY, Ho RC. Mental health strategies to combat the psychological impact of COVID-19 beyond paranoia and panic. Ann Acad Med Singap. 2020 Mar;49(1):155-60.

11. Saxena SK. Coronavirus disease 2019 (COVID-19) epidemiology, pathogenesis, diagnosis, and therapeutics. Singapore: Springer; 2020. DOI: https://doi.org/10.1007/978-981-15-4814-7

12. House JS, Landis KR, Umberson D. Social relationships and health. Science. 1988 Jul;241(4865):540-5.

13. Benson JA, McSorley VE, Hawkley LC, Lauderdale DS. Associations of loneliness and social isolation with actigraph and self-reported sleep quality in a national sample of older adults. Sleep. 2020 Jan;44(1):zsaa140. DOI: https://doi.org/10.1093/sleep/zsaa140

14. Wang J, Lloyd-Evans B, Giacco D, Forsyth R, Nebo C, Mann F, et al. Social isolation in mental health: a conceptual and methodological review. Soc Psychiatry Psychiatr Epidemiol. 2017 Oct;52(12):1451-61. DOI: https://doi.org/10.1007/s00127-017-1446-1

15. Schredl M, Bulkeley K. Dreaming and the COVID-19 pandemic: a survey in a U.S. sample. Dreaming. 2020;30(3):189-98.

16. Nielsen T, Svob C, Kuiken D. Dream-enacting behaviors in a normal population. Sleep. 2009 Dec;32(12):1629-32.

17. Gupta MA. Spontaneous reporting of onset of disturbing dreams and nightmares related to early life traumatic experiences during the COVID-19 pandemic by patients with posttraumatic stress disorder in remission. J Clin Sleep Med. 2020 Aug;16(8):1419-20. DOI: https:// doi.org/ $10.5664 /$ jcsm. 8562

18. Mollayeva T, Thurairajah P, Burton K, Mollayeva S, Shapiro CM, Colantonio A. The Pittsburgh sleep quality index as a screening tool for sleep dysfunction in clinical and non-clinical samples: a systematic review and meta-analysis. Sleep Med Rev. 2016;25:52-73. DOI: https:// doi.org/10.1016/i.smrv.2015.01.009

19. Buysse D, Reynolds C, Monk T, Berman SR, Kupfer DJ. The Pittsburgh sleep quality index: a new instrument for psychiatric practice and research. Psychiatry Res. 1989 May;28(2):193-213.

20. Escobar-Córdoba F, Eslava-Schmalbach J. Validación colombiana del índice de calidad de sueño de Pittsburgh España. Rev Neurol. 2005 Feb;40(3):150-5.

21. Jiménez-Genchi A, Monteverde-Maldonado E, Nenclares-Portocarrero A, Esquivel-Adame G, Vega-Pacheco A. Confiabilidad y análisis factorial de la versión en español del índice de calidad del sueño de Pittsburg en pacientes psiquiátricos. Gac Méd Méx. 2008;144(6):491-6.

22. Postuma RB, Arnulf I, Hogl B, Iranzo A, Miyamoto T, Dauvilliers Y, et al. A single-question screen for rapid eye movement sleep behavior disorder: a multicenter validation study. Mov Disord. 2012;27(7):913-6. DOI: http://dx.doi.org/10.1002/mds.25037

23. Pujol M, Pujol J, Alonso T, Fuentes A, Pallerola M, Freixenet J, et al. Idiopathic REM sleep behavior disorder in the elder Spanish community: a primary care center study with a two-stage design using video-polysomnographic. Sleep
Med. 2017 Dec;40:116-21. DOI: https://doi.org/10.1016/i.sleep.2017.07.021

24. Kroenke K, Spitzer RL, Williams JBW. The PHQ-9 validity of a brief depression severity measure. J Gen Intern Med. 2001 Sep;16(9):606-13. DOI: https://doi.org/10.1046/j.1525-1497.2001.016009606.x

25. Kroenke K, Spitzer RL. The PHQ-9: a new depression diagnostic and severity measure. Psychiatr Ann. 2002 Sep;32(9):509-15. DOI: https:// doi.org/10.3928/0048-5713-20020901-06

26. Baader T, Molina JL, Venezian S, Rojas CC, Farías RS, Fierro-Freinet C, et al. Validación y utilidad de la encuesta PHQ-9 (Patient Health Questionnaire) en el diagnóstico de depresión en pacientes usuarios de atención primaria en Chile. Rev Chil Neuro-Psiquiatr. 2012 Mar;50(1):1022. DOI: http://dx.doi.org/10.4067/s0717-92272012000100002

27. Spitzer RL, Kroenke K, Williams JB. A brief measure for assessing generalized anxiety disorder: the GAD-7. Arch Intern Med. 2006 May;166(10):1092-7.

28. Löwe B, Decker O, Müller S, Brähler E, Schellberg D, Herzog W, et al. Validation and standardization of the generalized anxiety disorder screener (GAD-7) in the general population. Med Care. 2008 Mar;46(3):266-74.

29. García-Campayo J, Zamorano E, Ruiz MA, Pardo A, Pérez-Páramo, LopezGomez V, et al. Cultural adaptation into Spanish of the generalized anxiety disorder-7 (GAD-7) scales a screening tool. Health Qual Life Outcomes. 2010;8:8. DOI: https://doi.org/101186/147-7525-8-8

30. Erren TC, Lewis P. SARS-CoV-2/COVID-19 and physical distancing: risk for circadian rhythm dysregulation, advice to alleviate it, and natural experiment research opportunities. Chronobiol Int. 2020 Jun;37(7):11069. DOI: https://doi.org/10.1080/07420528.2020.1772811

31. Kevin J, Gaston KJ, Davies TW, Nedelec SL, Holt LA. Impacts of artificial light at night on biological timings. Annu Rev Ecol Evol Syst. 2017;48:4968. DOI: https://doi.org/10.1146/annurev-ecolsys-110316-022745

32. Vigo DE, Cardinali DP. A diez años de la primera encuesta sobre prevalencia de alteraciones del sueño en poblaciones urbanas de América Latina: ¿cómo dormimos los argentinos?. Prensa Méd Argent. 2015; 101(5):278-82. 33. Hirshkowitz M, Whinton K, Albert SM, Alessi C, Bruno O, DonCarlos L, et al. National sleep foundation sleep time duration recommendations: methodology and results summary. Sleep Health. 2015 Mar;1(1):40-3.

34. Bouscoulet LT, Vázquez-García JC, Muiño A, Márquez M, López MV, Oca M, et al. Prevalence of sleep related symptoms in four Latin American cities. J Clin Sleep Med. 2008 Dec;4(6):579-85.

35. Giardino D, Huck-Iriat C, Riddick M, Garay A. The endless quarantine: the impact of the COVID-19 outbreak on healthcare workers after three months of mandatory social isolation in Argentina. Sleep Med. 2020 Dec;76:16-25. DOI: https://doi.org/10.1016/j.sleep.2020.09.022

36. American Psychiatric Association (APA). Diagnostic and statistical manual of mental disorders. 4th ed. Washington, DC: APA; 2000.

37. Schredl M. Nightmare disorder. In: Kushida C, ed. The encyclopedia of sleep. Waltham, MA: Academic Press; 2013. v. 4. p. 219-24.

38. Levin R, Fireman G. Nightmare prevalence, nightmare distress, and self-reported psychological disturbance. Sleep. 2002 Mar;25(2):205-12.

39 Bixler EO, Kales A, Soldatos CR, Kales JD, Healey S. Prevalence of sleep disorders in the Los Angeles metropolitan area. Am J Psychiatry. 1979;136(10):1257-62.

40. Janson C, Gislason T, Backer W, Plaschke P, Björnsson E, Hetta J, et al. Prevalence of sleep disturbances among young adults in three European countries. Sleep. 1995 Sep;18(7):589-97.

41. Schredl M. Nightmare frequency and nightmare topics in a representative German sample. Eur Arch Psychiatry Clin Neurosci. 2010 Dec;260(8):565-70.

42. Nielsen T, Carr M. Nightmares and nightmare function. In: Kryger M, Roth N, Dement WC, ed. Principles and practice of sleep medicine. 6th ed. Amsterdam: Elsevier; 2017. p. 546-54.

43. Cellini N, Canale N, Mioni G, Costa S. Changes in sleep pattern, sense of time and digital media use during COVID-19 lockdown in Italy. J Sleep Res. 2020;29(4):e13074. DOI: http://dx.doi.org/10.1111/jsr.13074

44. Schredl M, Bulkeley K. Dreaming and the COVID-19 pandemic: a survey in a U.S. sample. Dreaming. 2020;30(3):189-98.

45. Robert G, Zadra A. Thematic and content analysis of idiopathic nightmares and bad dreams. Sleep. 2014 Feb;37(3):409-17.

46. Zadra A. Variety and intensity of emotions in nightmares and bad dreams. J Nerv Ment Dis. 2006 Apr;194(4):249-54.

47. Nielsen T. The COVID-19 pandemic is changing our dreams. Scientific American 2020 October, 323, 4, 30-34 doi:10.1038/ scientificamerican1020-30

48. Bulkeley K. People may be remembering more dreams during the pandemic. Psychology Today. 2020 Apr; Available from: https://www. psychologytoday.com/us/blog/dreaming-in-the-digital-age/202004/ people-may-be-remembering-more-dreams-during-the-pandemic 
49. Walsh C. What pandemic dreams may come: Harvard researcher says many having nights full of bugs, masks, and natural disasters. The Harvard Gazette. 2020 May . Available from: https://news. harvard.edu/gazette/story/2020/05/harvard-researcher-says-dreamsindicative-of-virus-fears/

50 Ustun TB, Ayuso-Mateos JL, Chatterji S, Mathers C, Murray CJ. Global burden of depressive disorders in the year 2000. Br J Psychiatry. 2004 May;184:386-92.

51. Soria V, Urretavizcaya M. Circadian rhythms and depression. Actas Esp Psiquiatr. 2009;37(4):222-24.

52. Linkowski P, Kerkhofs M, Van Onderbergen A, Hubain P, Copinschi G, L'Hermite-Balériaux M, et al. The 24-hour profiles of cortisol, prolactin, and growth hormone secretion in mania. Arch Gen Psychiatry. 1994 Aug;51(8):616-24.

53. Souetre E, Salvati E, Belugou JL, Pringuei D, Candito M, Krebs B, et al. Circadian rhythms in depression and recovery: Evidence for blunted amplitude as the main chronobiological abnormality. PsychiatryReserch 1988 Jun;28(3):263-78.

54. Franzen PL, Buysse DJ. Sleep disturbances and depression: risk relationships for subsequent depression and therapeutic implications. Dialogues Clin Neurosci. 2008 Dec;10(4):473-81.

55. Cañellas F, Collado C. Enfermedades psiquiátricas y sueño. In: Sociedad Española de Sueño, ed. Tratado de Medicina del sueño. Madrid: Editorial Médica Panamericana; 2015. p. 701-725.

56. Insa SP, Gascón JB. RTM-IV recomendaciones terapéuticas en los trastornos mentales. 4th ed. Barcelona: CYESAN; 2012.

57. Mead GE, Morley W, Cambell P, Greig CA, McMurdo M, Lawlor DA. Exercise for depression. Cochrane Database Syst Rev. 2009 Oct;(4):CD004366.

58. Terman M, Terman JS. Light therapy for seasonal and nonseasonal depression: efficacy, protocol, safety, and side effects. CNS Spectrums. 2004;10(8):647-63.
59. Most EI, Scheltens P, Van Someren EJW. Prevention of depression and sleep disturbances in elderly with memory-problems by activation of biological clock with light-a randomized clinical trial. Trials. 2010;11:19.

60. Sparks SW. Posttraumatic stress syndrome: what is it?. J Trauma Nurs. 2018 Jan/Feb;25(1):60-5. DOI: https://doi.org/10.1097/ JTN.0000000000000343

61. Forte G, Favieri F, Tambelli R, Casagrande M. COVID-19 pandemic in the Italian population: validation of a post-traumatic stress disorder questionnaire and prevalence of PTSD symptomatology. Int J Environ Res Public Health. 2020;17(11):4151. DOI: https://doi.org/10.3390/ ijerph17114151

62. Forte G, Favieri F, Tambelli R, Casagrande M. The enemy which sealed the world: effects of COVID-19 diffusion on the psychological state of the Italian population. J Clin Med. 2020 Jun;9(6):1802. DOI: https:// doi.org/10.3390/jcm9061802

63. Hawryluck L, Gold WL, Robinson S, Pogorski S, Galea S, Styra R. SARS control and psychological effects of quarantine, Toronto, Canada. Emerg Infect Dis. 2004 Jul;10(7):1206-12.

64. Torrente F, Yoris A, Low D, Lopez P, Bekinschetein P, Manes F, et al. Sooner than you think: a very early affective reaction to the COVID-19 pandemic and quarantine in Argentina. J Affect Disord. 2020 Aug 04, [Epub preprint]. DOI: https://doi.org/10.1101/2020.07.31.20166272

65. Barone DA. Dream enactment behavior - a real nightmare: a review of post-traumatic stress disorder, REM sleep behavior disorder, and trauma associated sleep disorder. J Clin Sleep Med. 2020 Nov;16(11):1943-8.

66. Baltzan M, Yao C, Rao C, Rizzo D, Postuma R. Dream enactment behavior: review for the clinician. J Clin Sleep Med. 2020 Nov;16(11):1949-69. 